\title{
Construction and characterization of an infectious cDNA clone of coxsackievirus
}

A 10

Qiliang Liu ${ }^{1,2}$, Hanliang Dan ${ }^{3}$, Xiaoping Zhao ${ }^{3}$, Huoying Chen ${ }^{1}$, Yongbei Chen ${ }^{1}$, Ning Zhang ${ }^{1}$, Zhijing Mo ${ }^{2^{*}}$ and Hongbo Liu' ${ }^{1,4^{*}}$

\begin{abstract}
Background: Coxsackievirus A10 (CA10) constitutes one of the four major pathogens causing hand, foot and mouth disease in infants. Infectious clones are of great importance for studying viral gene functions and pathogenic mechanism. However, there is no report on the construction of CA10 infectious clones.
\end{abstract}

Methods: The whole genome of CA10 derived from a clinical isolate was amplified into two fragments and ligated into a linearized plasmid vector in one step by In-Fusion Cloning. The obtained CA10 CDNA clones and plasmids encoding T7 RNA polymerase were co-transfected into 293 T cells to rescue CA10 virus. The rescued virus was identified by SDS-PAGE, Western blotting and transmission electron microscopic. One-day-old ICR mice were intracerebrally inoculated with the CA10 virus and clinical symptoms were observed. Multiple tissues of moribund mice were harvested for analysis of pathogenic changes and viral distribution by using H\&E staining, real-time PCR and immunohistochemical staining.

Results: CA10 viruses were rescued from the constructed cDNA clone and reached a maximum titer of $10^{8.125} \mathrm{TCID}_{50} / \mathrm{mL}$ after one generation in RD cells. The virus exhibited similar physical and chemical properties to those of the parental virus. It also showed high virulence and the ability to induce death of neonatal ICR mice. Severe necrotizing myositis, intestinal villus interstitial edema and severe alveolar shrinkage were observed in infected mice. The viral antigen and the maximum amount of viral RNA were detected in limb skeletal muscles, which suggested that the limb skeletal muscles were the most likely site of viral replication.

Conclusion: Infectious clones of CA10 were successfully constructed for the first time, which will facilitate the establishment of standardized neonatal mouse models infected with CA10 for the evaluation of vaccines and antiviral drugs, as well as preservation and sharing of model strains.

Keywords: Coxsackievirus A10, Infectious clone, ICR mouse, Mouse model

\section{Background}

Hand, foot and mouth disease (HFMD) is typically a contagious childhood illness caused by human enterovirus (EV). Enterovirus A71 (EV71) and coxsackievirus A16 (CA16) are the primary pathogens associated with HFMD, while the proportion of HFMD caused by coxsackievirus A10 (CA10) has been increasing in recent years in

\footnotetext{
* Correspondence: mozhijing@glmc.edu.cn; hbliu@glmc.edu.cn

${ }^{2}$ College of Bio-technology, Guilin Medical University, Guilin, Guangxi, China ${ }^{1}$ Department of Laboratory Medicine, The Second Affiliated Hospital of Guilin Medical University, Guilin, Guangxi, China

Full list of author information is available at the end of the article
}

different geographical areas(e.g., China [1-3], Finland [4], France [5], Thailand [6], Vietnam [7] and India [8]). In addition, CA10-associated HFMD commonly shows mild and self-limiting symptoms; nonetheless, a few cases present with various severe clinical manifestations, such as onychomadesis, herpangina, hyperCKemia, encephalitis, acute flaccid paralysis, neurorespiratory syndrome, and even death [5, 9-12]. Moreover, co-circulation of CA10 and other enteroviruses, such as EV71, CA16, and coxsackievirus A6 (CA6), increases the chance of genetic recombination and the emergence of new genetic variants of these viruses $[3,4,13]$. At present, with no effective

(C) The Author(s). 2019 Open Access This article is distributed under the terms of the Creative Commons Attribution 4.0 International License (http://creativecommons.org/licenses/by/4.0/), which permits unrestricted use, distribution, and 
vaccine and antiviral drugs, HFMD caused by CA10 has been a public health problem worldwide. Therefore, it is urgent to investigate infection mechanism and develop novel vaccines for the CA10 virus.

Infectious clones play an extremely substantial role in RNA virus research by reason that RNA genomes are difficult to preserve and manipulate. Besides, CA10 is a member of the enterovirus genus of the Picornaviridae family. Its genome is a positive single-stranded RNA with a length of approximately 7400 nucleotides, which has a single open reading frame (ORF) that is flanked by untranslated regions (UTRs) at the $5^{\prime}$ and $3^{\prime}$ ends. Research activities related to the viral pathogenesis, the functions of viral genes, viral infection and replication or vaccine development commonly involve genetic manipulations of enterovirus genome, which is nearly impossible to be conducted without an infectious cDNA clone of the viral genome. Infectious cDNA clones of several enteroviruses have been successfully constructed, including poliovirus, EV71 [14], CA16 [15], CA6 [16], CB3 [17], ECHO30 [18], ECHO25 [19], etc. However, there were no reports concerning CA10 infectious clones.

In the present study, an infectious clone from a strain of CA10 was established. The recovered CA10 virus had the same morphological and infectious characteristics with its parent strain. Moreover, it exhibited strong muscular tropism, induced multiple tissue damage and caused severe clinical symptoms or even death in neonatal mice. The construction of CA10 infectious clones may facilitate the next researches on CA10 pathogenic mechanism, vaccine development, etc.

\section{Methods}

\section{Cell culture and virus}

Human rhabdomyosarcoma (RD) cells were maintained in Dulbecco's Modified Eagle Medium (DMEM; Gibco, Waltham, MA, USA) supplemented with $10 \%$ fetal bovine serum (FBS) (Gibco; Waltham, MA, USA), $100 \mathrm{U} /$ $\mathrm{mL}$ penicillin, and $100 \mu \mathrm{g} / \mathrm{mL}$ streptomycin at $37^{\circ} \mathrm{C}$ in presence of $5 \% \mathrm{CO}_{2}$. The CVA10 strain, $\mathrm{P} 148 / \mathrm{ZS} / \mathrm{CHN} /$ 2012 (No. MK645898), isolated from a clinical patient in Zhongshan area (Guangdong province, China), was propagated in $\mathrm{RD}$ cells and stored at $-80^{\circ} \mathrm{C}$ in our laboratory.

\section{RNA extraction and reverse transcription polymerase chain reaction}

CA10 was harvested in infected RD cellular supernatant after three freeze-thaw cycles and centrifugation. The viral RNA was extracted using QIAamp Viral RNA Mini Kit (Qiagen, Hilden, Germany), and then was reverse transcribed using PrimeScript ${ }^{\mathrm{tm}}$ II 1st Strand cDNA Synthesis Kit (Takara, Osaka, Japan), according to the manufacturer's instructions. The synthesized first strand cDNA was used as a template for subsequent PCR amplification of CA10 genome fragments.

\section{Cloning of the full-length CDNA and T7 RNA polymerase DNA}

The In-Fusion Coning strategy was used to construct the infectious clone of CA10, as shown in Fig. 1a. Primers were designed based on the CA10 genome sequence and the pSVA sequence. Primers (pSVA-R/
A

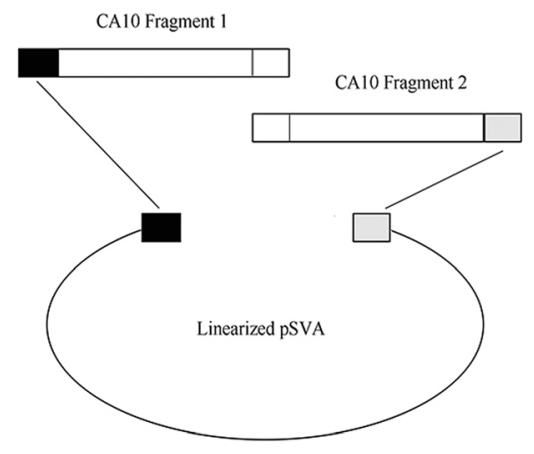

B

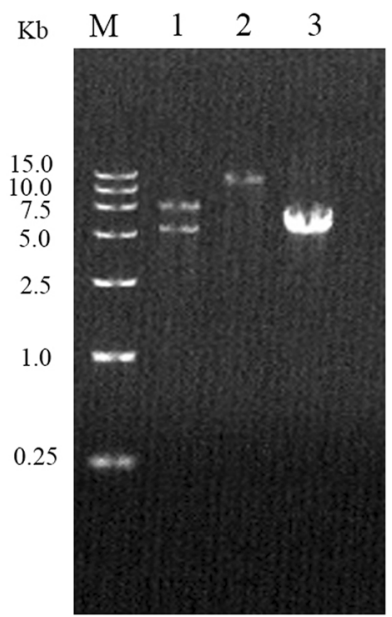

Fig. 1 Construction of a full-length cDNA clone of CA10. a Schematic representation of construction of the full-length cDNA clone of CA10 by InFusion Cloning strategy. $\mathbf{b}$ Lane M is the DL15,000 DNA marker; Lanes 1 and 2 show the results of double (the band near 5.0 kb is the linearized pSVA vector and the band near the $7.5 \mathrm{~kb}$ is the (A10 DNA) and single enzyme digestion compared with the linearized pSVA vector for control (Lane 3) 
CA10-F1，CA10-R1/CA10-F2，CA10-R2/pSVA-F) had an overlap of 20 bases (Table. 1). The pSVA vector, containing T7 promoter, was linearized by PCR using PrimeSTAR $^{\circ}$ GXL DNA Polymerase (Takara, Osaka, Japan) with $\mathrm{pSVA-F/R}$ primers. The genome of CA10 was amplified into two fragments with CA10-F1/R1 (for CA10 fragment-1) and CA10-F2/R2 (for CA10 fragment-2) primers. Then, the pSVA vector, CA10 fragment- 1 and CA10 fragment-2 were assembled using In-Fusion ${ }^{\circ}$ HD Cloning Kit (Takara, Osaka, Japan), resulting in plasmid pSVA-CA10. Then, the pSVA-CA10 clone was sequenced by Beijing Genomics Institute (Beijing, China). The T7 RNA polymerase gene was codon-optimized for mammalian cells, synthesized and then cloned into pLVX-Puro vectors by Beijing Genomics Institute.

\section{Co-transfection to rescue virus}

To rescue the CA10 virus, $293 \mathrm{~T}$ cells seeded at density of $5 \times 10^{5}$ cells / well into a 6 -well plate were grown in $\mathrm{Opti}^{-\mathrm{MEM}^{\circ} \mathrm{I}}$ reduced serum medium (Gibco, Waltham, MA, USA) without antibiotics for $24 \mathrm{~h}$. The co-transfection mixture, which contained $1 \mu \mathrm{g}$ pSVA-CA10 DNA, $1.5 \mu \mathrm{g}$ pLVX-Puro-T7 RNA polymerase DNA, $7.5 \mu \mathrm{L}$ P3000 ${ }^{\mathrm{mm}}$ Reagent, $10 \mu \mathrm{L}$ Lipofectamine $^{\mathrm{Tm}} 3000$ Reagent and $250 \mu \mathrm{L}$ Opti-MEM medium per well was prepared according to Lipofectamine $^{\mathrm{TM}} 3000$ Reagent (Thermo Fisher Scientific, Waltham, MA, USA) protocol and inoculated into $293 \mathrm{~T}$ cells and incubated for 3 days at $37^{\circ} \mathrm{C}$. The rescued CA10 viruses were harvested by freeze-thawing. The supernatant was then inoculated to RD cells in serum-free DMEM medium. At $24 \mathrm{~h}$ post-inoculation, the cells displayed almost $80 \%$ cytopathic effect (CPE), suggesting that the co-transfection of pSVA-CA10 DNA with pLVX-Puro-T7 RNA polymerase DNA can produce infectious viruses.

\section{Virus titration}

Virus titers were determined by microtitration using RD cells and expressed as the $50 \%$ tissue culture infectious dose $\left(\mathrm{TCID}_{50}\right)$. Briefly, 96-well plates were seeded with a

Table 1 Primers used for the construction of CA10 infection clones

\begin{tabular}{|c|c|}
\hline Primer name & Sequence $\left(5^{\prime}-3^{\prime}\right)$ \\
\hline$\overline{p S V A-F}$ & GTCGACAATTCTCATGTTTGACAGC \\
\hline pSVA-R & CCTATAGTGAGTCGTATTACGCGGC \\
\hline CA10-F1 & $\begin{array}{l}\text { GTAATACGACTCACTATAGGTTTAA } \\
\text { AACAGCCTGTGGGTTGTACC }\end{array}$ \\
\hline CA10-R1 & CGCCGAGTCCCTTGATATAGTCAGACACTCCCTG \\
\hline CA10-F2 & CTATATCAAGGGACTCGGCGATGCTITT \\
\hline CA10-R2 & $\begin{array}{l}\text { CAAACATGAGAATTGTCGACTIITITा } \\
\text { TIIIITITITITTGCTATTC }\end{array}$ \\
\hline
\end{tabular}

density of $1 \times 10^{4}$ cells/ well in DMEM supplemented with $10 \% \mathrm{FBS}$ and incubated at $37{ }^{\circ} \mathrm{C}$ for $24 \mathrm{~h}$ prior to infection with serial dilutions of the virus. Each dilution was inoculated with 8 wells for $200 \mu \mathrm{L}$ per well. The plates were cultured for 8-10 days, and observed for $\mathrm{CPE}$. The $\mathrm{TCID}_{50}$ values were calculated according to the Reed-Muench method [20].

\section{Purification of viruses and transmission electron microscopy (TEM)}

To purify CA10 particles, the virus culture supernatant was harvested and the cell debris was removed by three times of centrifugation at $8000 \mathrm{rpm}$ using a \#3335 rotor (Thermo Fisher Scientific, Waltham, MA, USA) for 20 min each time. The virus sample was precipitated by incubation with $8 \%$ polyethylene glycol (PEG) 8,000 in 0.5 $\mathrm{M} \mathrm{NaCl}$ at $4{ }^{\circ} \mathrm{C}$ for $12 \mathrm{~h}$. The mixture was centrifuged using a 45Ti rotor (Beckman Coulter Inc., Brea, CA, USA) at $24,000 \mathrm{rpm}$ for $30 \mathrm{~min}$ at $4{ }^{\circ} \mathrm{C}$. The pellets were resuspended in phosphate-buffered saline (PBS) and further purified by a 10 50\% continuous sucrose gradient centrifugation at $32,000 \mathrm{rpm}$ in a SW60 rotor at $4{ }^{\circ} \mathrm{C}$ for $3 \mathrm{~h}$. The fractions at $20 \sim 40 \%$ sucrose were collected and dialyzed against three exchanges of $500 \mathrm{~mL}$ PBS at $\mathrm{pH}$ 7.4, and then stored at $4{ }^{\circ} \mathrm{C}$. The formation of CA10 particles was analyzed by negative staining electron microscopy according to a previously described method [21]. Briefly, purified viruses were adsorbed to 200 mesh carbon-coated copper grids and incubated for $10 \mathrm{~min}$ at room temperature. The grids were then washed once with PBS and stained for $45 \mathrm{~s}$ with $2 \%$ phosphotungstic acid. Specimens were evaluated using an electron microscope.

\section{SDS-PAGE and Western blotting}

SDS-PAGE analysis of CA10 virus was performed in $10 \%$ SDS polyacrylamide gels according to the protocol as previously described [21]. For immunoblotting, CA10 viral proteins were directly electro-transferred onto the polyvinylidene difluoride (PVDF) membrane and probed with mouse anti-CA10 VP1 antibody, followed by a corresponding horseradish peroxidase (HRP)-conjugated secondary antibody. Membranes were developed by Pierce $^{\text {ru }}$ ECL Plus Western Blotting Substrate (Thermo Fisher Scientific, Waltham, MA, USA) and signals were recorded by a gel imaging system (Chemi-Doc $\mathrm{XRS}^{+}$; Bio-Rad Laboratories, Inc., Hercules, CA, USA).

\section{Animal experiments}

Specific pathogen-free (SPF) Institute of Cancer Research (ICR) pregnant mice were purchased from Silaikejingda Laboratory Animal Co., Ltd., Hunan, China. All animal experiments were undertaken in accordance with protocols approved by the Institutional Animal Care and 
Use Committee and Ethics Committee of Guilin Medical University (Guilin, China). To evaluate the virulence of the rescued CA10, grouped one-day-old ICR mice were intracerebrally challenged with 10 -fold serial dilution $\left(10^{7} \sim 10^{1} \mathrm{TCID}_{50}\right)$ of passaged CA10 $(20 \mu \mathrm{L}$ CA10 sample per mouse). The control mice were injected with $20 \mu \mathrm{L}$ of PBS via the same route and maintained in a separate cage from the infected mice. Every group contained 8 neonatal ICR mice, and all mice were monitored daily for body weight, clinical illness and death until 21 days post-infection. Clinical grading was carried out as previously reported [22]: 0 , healthy; 1 , lethargy and inactivity; 2, wasting; 3, limb-shake weakness; 4, hind-limb paralysis; and 5, moribund and death.

\section{Real-time PCR}

Total RNAs were extracted using MiniBEST Universal RNA Extraction Kit (Takara, Osaka, Japan) from the same weight of tissue homogenates (brain, intestine, limb skeletal muscles, heart, liver, and lung), respectively, and then were reverse transcribed with PrimeScript $^{\mathrm{mu}}$ RT reagent Kit (Takara, Osaka, Japan) according to the manufacturer's instructions. For quantification, real-time PCR analysis was performed by using TB Green ${ }^{\text {tm }}$ Fast qPCR Mix (Takara, Osaka, Japan) with primers (Forward, 5'-GGCGATCCTGTG GAGGATATAAT-3', Reverse, 5' - TCTCTAATCGGT GTGAACTGGGA-3') in Bio-Rad CFX96 system (BioRad Laboratories, Inc., Hercules, CA, USA). Real-time PCR procedure was conducted as follows: for $15 \mathrm{~min}$ at $95^{\circ} \mathrm{C}$, followed by 40 cycles of $95^{\circ} \mathrm{C}$ for $10 \mathrm{~s}, 60^{\circ} \mathrm{C}$ for $20 \mathrm{~s}$ and $72{ }^{\circ} \mathrm{C}$ for $20 \mathrm{~s}$. The quantified pSVA-CA 10 plasmid was 10 -fold serial diluted and used as standard sample for generating a standard curve. Virus loads were expressed as $\log 10$ copies/mg of tissues.

\section{Histopathological and immunohistochemical analysis}

For histopathological and immunohistochemical analysis, each of one-day-old ICR mice infected with $20 \mu \mathrm{L}$ of $10^{4} \mathrm{TCID}_{50}$ CA10 in a moribund state or with PBS as control was euthanized. Brain, limb skeletal muscles, intestines, and lung were separately harvested and immediately fixed by $4 \%$ formalin/PBS for at least $3 \mathrm{~h}$ at room temperature. Fixed tissues were bisected, embedded in paraffin and sectioned on thickness of $4 \mathrm{~mm}$. For histopathological examination, tissue slices were stained with hematoxylin and eosin (H\&E). For immunohistochemical testing, tissue slices were dewaxed, dehydrated, and microwaved for $20 \mathrm{~min}$ at $90^{\circ} \mathrm{C}$ in a citrate buffer. A mouse anti-CA10 monoclonal antibody L8F12 (1:1000 dilution; gifted by Professor Xia's laboratory, Xiamen University, Xiamen, China) was applied for $1 \mathrm{~h}$ at $37^{\circ} \mathrm{C}$. The peroxidase-conjugated secondary antibody was added for $30 \mathrm{~min}$ at room temperature, and then developed by diaminobenzidine tetrahydrochloride (DAB) chromogen solution (Fuzhou Maixin Biotechnology Development Co., Ltd., Fuzhou, China).

\section{Statistical analysis}

The survival rates were evaluated by the Mantel-Cox log-rank test. The clinical scores and the average body weights were compared using Dunn's multiplecomparison test. $P$-values $(P)$ less than 0.05 were considered statistically significant.

\section{Results}

Construction of a full-length CDNA clone of CA10 via the in-fusion cloning strategy

The overall strategy to construct the infectious clone of CA10 is shown in Fig. 1a. The viral RNA was extracted and reverse transcribed using oligo (dT) primers. Two overlapped CA10 DNA fragment-1 and fragment- 2 were amplified from the first strand cDNA. Fragment 1 contained 20 nucleotides of linearized pSVA vector at $5^{\prime}$ end and 1-3813 bp of the CA10 genome, while fragment- 2 contained 20 nucleotides of linearized pSVA vector at $3^{\prime}$ end and 3794-7411 of the CA10 genome with poly(A) tails of 25 bases in length. The pSVA vector was linearized by PCR. The pSVA vector, CA10 DNA fragment-1and fragment-2 were then assembled to construct pSVA-CA10 plasmids using an In-Fusion Cloning Kit. Double (Not I/Sal I) and single (Not I) enzyme digestion identification showed that the length of CA10 genome, pSVA and pSVA-CA10 were all correct (Fig. 1b). The sequence of pSVA-CA10 was determined and there was no nucleotide mutation compared with the original CA10 strain sequence.

Recovery and physicochemical feature of infectious CA10 from the cDNA clone

To recover CA10 virus, pSVA-CA10 and pLVX-PuroT7-RNA polymerase DNA were co-transfected into 293

$\mathrm{T}$ cells. After $72 \mathrm{~h}$, the supernatant was harvested and then used to infect RD cells. After another $72 \mathrm{~h}$, cells were analyzed by a microscope, the cell supernatant was harvested and the titer of viruses was measured and cell precipitates were analyzed by biochemical assays. The recovered virus reached a maximum titer of $10^{8.125} \mathrm{~T}$ $\mathrm{CID}_{50} / \mathrm{mL}$. As illustrated in Fig. 2a, the negative control (NC) RD cells appeared to grow normally, whereas the recovered CA10 (Fig. 2b) and the wild CA10 (Fig. 2c) infected cells displayed severe CPE. As shown in Fig. 2d, VP1 and VP3 proteins were detected in the supernatants of the RD cells infected with recovered CA10 or wild CA10 by SDS-PAGE. As shown in Fig. 2e, VP1 protein was detected by Western blotting in the supernatant of the RD cells infected with recovered CA10 or wild CA10. For morphological characterization of 
A

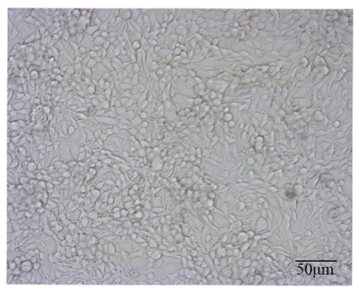

B

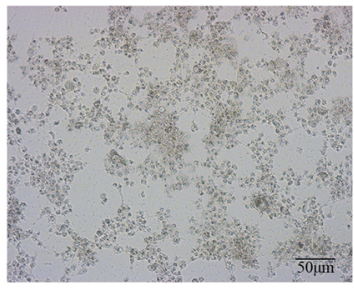

C

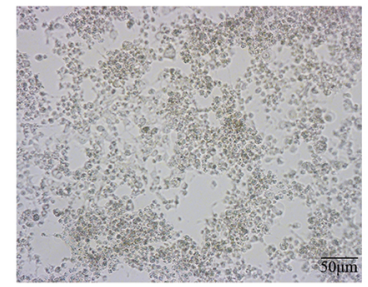

D $\quad 256$

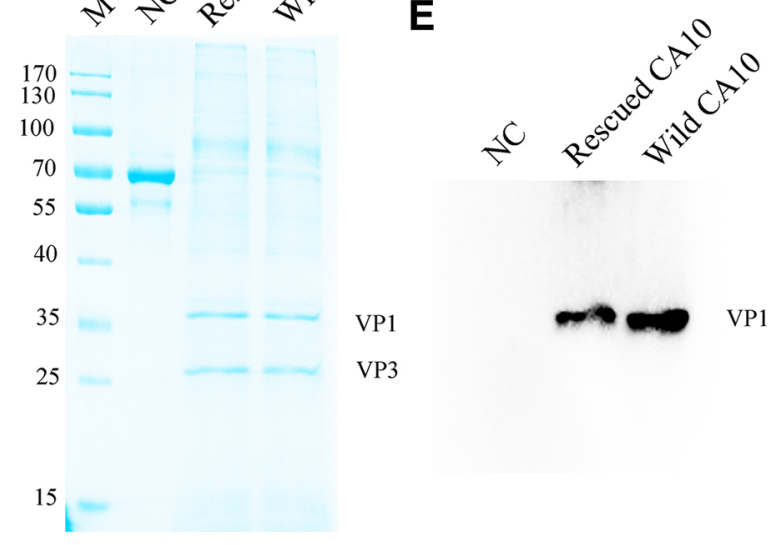

$\mathbf{F}$

G
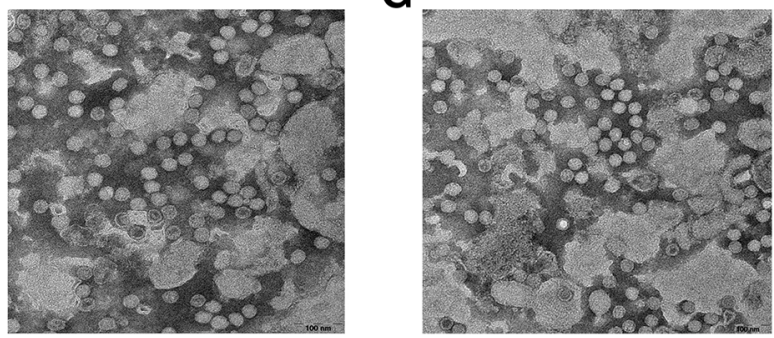

Fig. 2 Identification of recovered CA10 from the CDNA clone. a Normal RD cells without infected virus. b Cytopathic effects displayed in RD cells were infected with the rescued viruses. $\mathbf{c}$ Cytopathic effects displayed in RD cells were infected with the wild CA10 viruses. $\mathbf{d}$ Identification of recovered CA10 and the wild CA10 by SDS-PAGE and (e) Western blotting. $\mathbf{f}$ and $\mathbf{g}$ are electron microscopic examinations of the purified recovered CA10 and wild CA10 particles. The scale bar is $100 \mathrm{~nm}$

the rescued viruses, the viral particles were observed under TEM with magnification of $30000 \times$. The rescued CA10 (Fig. 2f) or wild CA10 (Fig. 2g) particles were both about $30 \mathrm{~nm}$ in diameter, which were in agreement with the diameter of other enteroviruses of the Piconaviridae family. In addition, the growth rates between the wild and rescued CA10 viruses showed no significant difference, as shown in Fig. 3.

\section{CA10 infection in one-day-old mice resulted in severe illness and death}

To assess the virulence of rescued CA10, 7 groups of one- day-old ICR mice were challenged with 10 -fold serial dilution of recovered CA10 $\left(10^{7}-10^{1} \mathrm{TCID}_{50}\right)$ via intracerebral routes. Negative controls were alternatively challenged with PBS. The survival percentage, mean body weight, and average clinical scores were indicated 


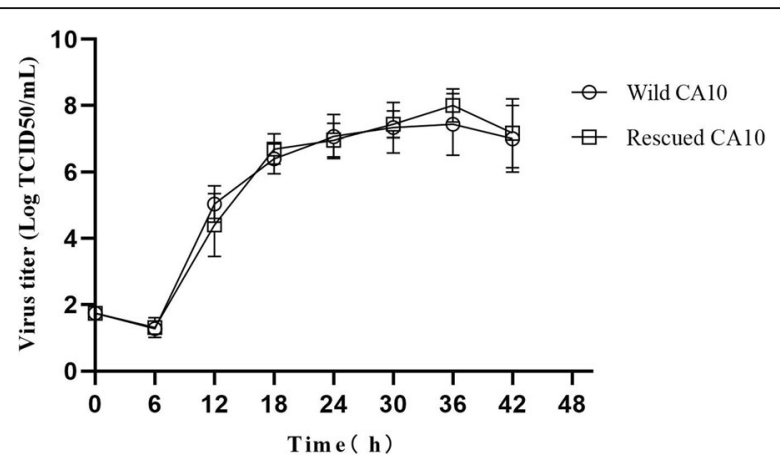

Fig. 3 One-step growth curves of the wild and rescued CA10 viruses were analyzed by infecting RD cells with viruses at 50 $\mathrm{TCID}_{50}$ per well in 12-well plates. The supernatant was collected at $0,6,12,18,24,30,36$ and $42 \mathrm{~h}$ after infection and titrated using a microtitration assay. At each time point, titer values are means of the three samples. Error bars represent the standard deviation from triplicate experiments

in Fig. 4. The severity of clinical symptoms, from mild to severe, was scored as five grades. The mortality of the $10^{7} \sim 10^{3} \mathrm{TCID}_{50}$ group was $100 \%$, and the mean clinical scores were at grade 5 at 4 days post-infection. The survival rate of the $10^{2} \mathrm{TCID}_{50}$ group was $25 \%$, and the mean clinical scores were above grade 4 at 5 days postinfection, then decreased under grade 4 at 16 days postinfection. There was no death in $10^{1} \mathrm{TCID}_{50}$ group, and the mean weight had no significant difference from negative control. The mean clinical scores of the $10^{1}$ TCID $_{50}$ group were grade 3 at 4 days post-infection and decreased to 0 at 17 days post-infection. The MantelCox log-rank test indicated that there was statistically significant difference in survival rates between NC group and $10^{7}-10^{2}$ TCID $_{50}$ groups. Dunn's multiplecomparison test revealed that there was statistically significant difference in mean body weight between $\mathrm{NC}$ group and $10^{7}-10^{2} \mathrm{TCID}_{50}$ groups, and in mean clinical scores between $\mathrm{NC}$ group and $10^{7}-10^{1}$ TCID $_{50}$ groups. (*****: $P<0.0001$; **: $\left.P<0.01\right)$.

\section{Pathological changes and viral distributions in infected mice after intracerebral challenge with a lethal dose of recovered CA10}

To investigate the pathological changes, multiple tissues of neonatal ICR mice infected with CVA10 in a moribund state were examined by H\&E staining. The limb skeletal muscle of infected mice exhibited severe necrotizing myositis, and muscle fibers were irregularly scattered in fractures or disappeared (Fig. 5b). The small intestine of some infected mice showed intestinal villus interstitial edema and scattered epithelial cell vacuolar degeneration (Fig. 5d). Meanwhile, the lung of infected mice showed severe alveolar shrinkage, vascular dilatation and congestion, while no pulmonary fibrosis and inflammatory cell infiltration were found (Fig. 5f). In addition, no obvious pathological change observed in the brain, heart or liver and no viral antigen was detected in brain, heart, liver, intestine or lung (data were not shown). For determination of viral distribution, viral RNA in tissues was quantified by real-time PCR, and viral antigen was detected by immunohistochemical staining. The real-time PCR results showed that the amount of virus RNA was maximum in limb skeletal muscle $\left(8.9 \times 10^{8}\right.$ copies $\left./ \mathrm{mL}\right)$. The immunohistochemical staining indicated that CA10 antigen was only detected in limb skeletal muscles (Fig. 5h), which suggested the limb skeletal muscle as the most likely site for in vivo replication.

\section{Discussion}

The development of infectious clone technology enables manipulation of RNA viruses at the molecular level and provides an effective method for the study of the structure and function of RNA virus genomes. In this study, we, for the first time, exhibited the construction of an infectious full-length CA10 cDNA clone from the P148/ $\mathrm{ZS} / \mathrm{CHN} / 2012$ strain, as well as recovery of CA10 viruses from the infectious clone. Our data demonstrated that co-transfection of pSVA-CA10 DNA with pLVXPuro-T7 RNA polymerase DNA could produce infectious rescued CA10 viruses. The recovered CA10 was compared with the wild CA10 virus by CPE, SDS-PAGE, western blotting, TEM and growth rates. The results showed that the rescued virus and its parental strain shared similar physical and chemical characteristics, which proved that the CA10 infectious clone had been successfully constructed and could be used as a specific template for preservation of the CA10 strain.

In previous studies, infectious clones were successfully developed for a number of enteroviruses with different methods. EV71 or CA16 cDNA clones were established by assembling segmented cDNA fragments of the viral genome into a DNA vector via specific cleavage sites [15, 23, 24], and CA6 or Echo25 cDNA clones were constructed by utilizing In-Fusion Cloning to assemble the full length of viral genome and vector, which was difficult to operate. $[16,19]$. In the present study, the CA10 genome was amplified into two close-sized segments, and the two DNA segments were connected to the linearized vector using the In-Fusion Cloning only in one step.

Furthermore, the virulence of the recovered CA10 virus in neonatal mice was evaluated, the organ or tissue lesions caused by the virus in vivo were analyzed by H\&E staining, and the main tissue of the virus distribution in infected mice was investigated by immunohistochemistry and real-time PCR. The results disclosed that the mortality of the challenged 
A

Challenged by infectious clone of CA10

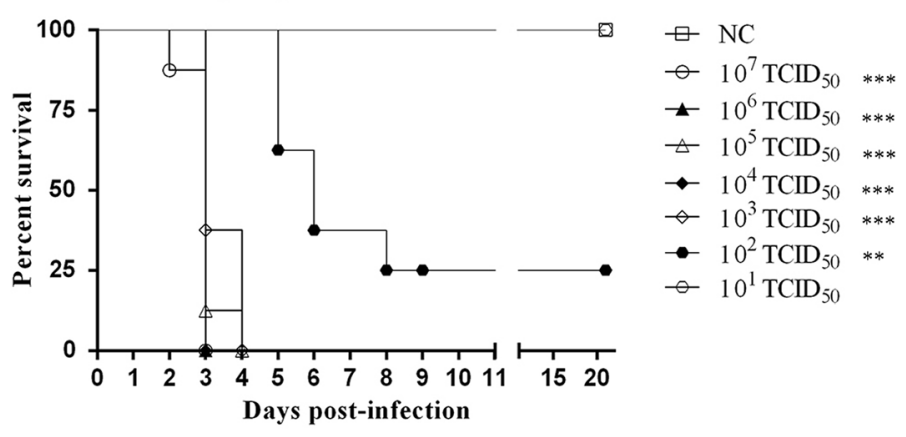

B

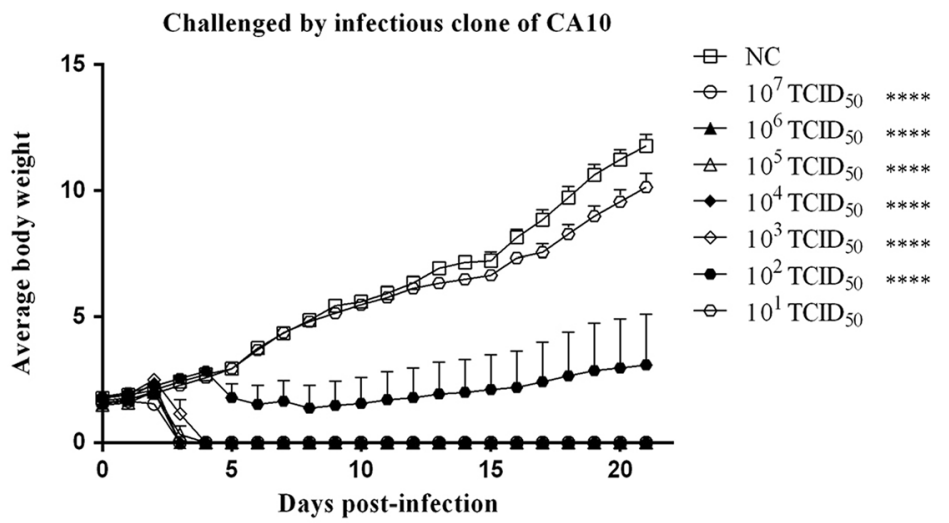

C

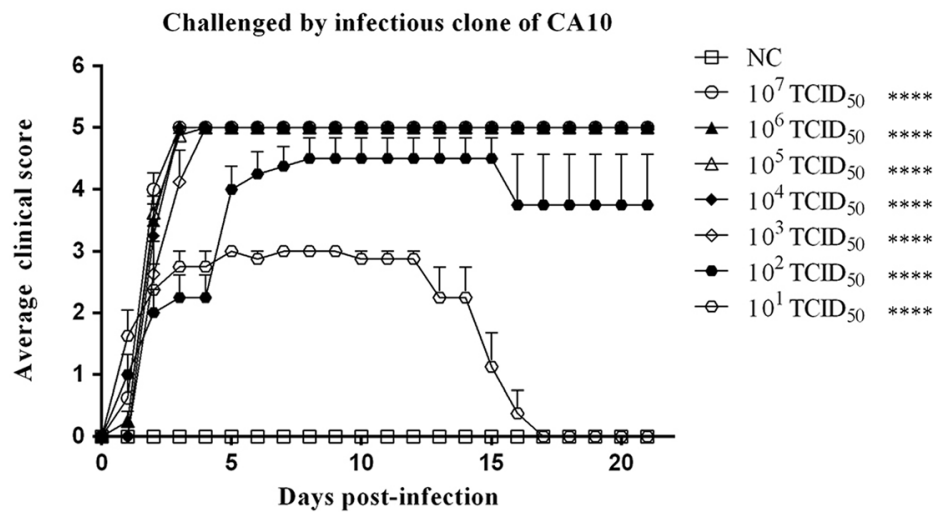

Fig. 4 The virulence evaluation of the rescued CA10 viruses. Seven groups of one-day-old ICR mice were challenged with 10-fold serial dilution of recovered CA10 (10 TCID50 10 TCID50) via intracerebral routes. a Survival curve of the neonatal mice. $\mathbf{b}$ Average body weight of the neonatal mice. $\mathbf{c}$ Health scores of the neonatal mice. The survival rates were evaluated by the Mantel-Cox log-rank test. The clinical scores and the body weight were compared using Dunn's multiple-comparison test. ${ }^{* * *}: P<0.0001,{ }^{* * *}: P<0.001,{ }^{* *}: P<0.01$

mice was increased with the increase of virus concentrations, and mice in $10^{7}-10^{3} \mathrm{TCID}_{50}$ dilution groups showed severe clinical signs, such as wasting, limb-shake weakness and hind-limb paralysis. The histopathological analysis showed that CA10 infection induced obvious tissue lesions, including scattered limb skeletal muscle fibers, intestinal villus interstitial edema and alveolar shrinkage, however, notable inflammatory symptoms were not detected in the majority of tissues. Additionally, in contrast to other types of enterovirus, EV71 and CA16 not only had a muscle tropism, but also could enter the brain 
A

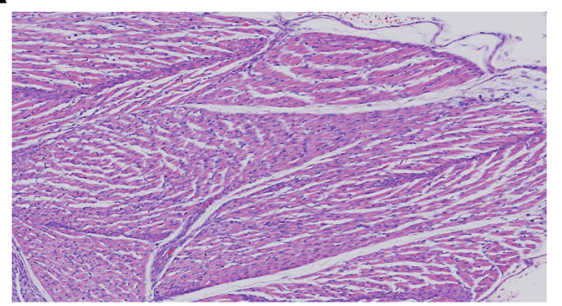

C

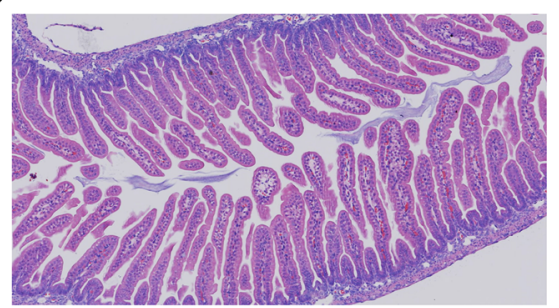

E

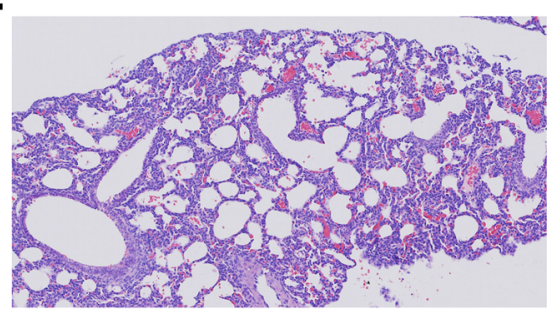

G

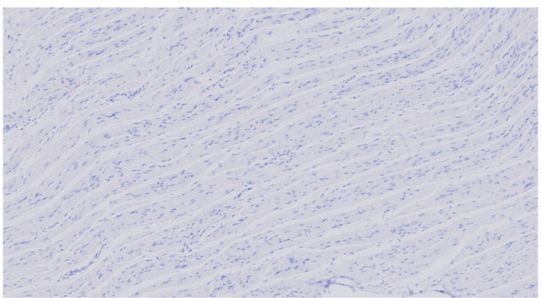

B

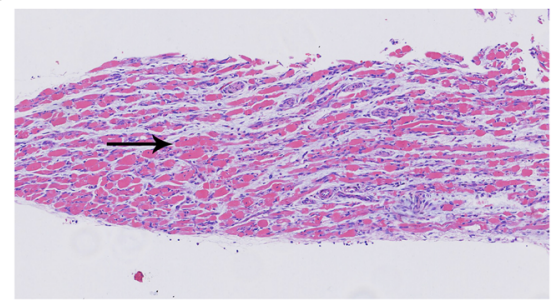

D

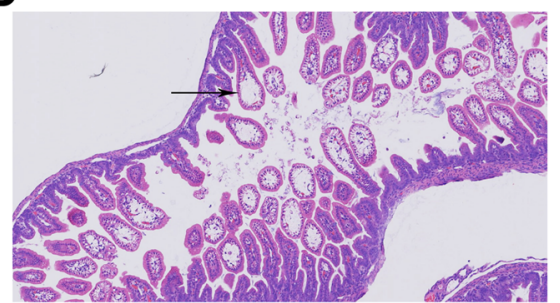

F

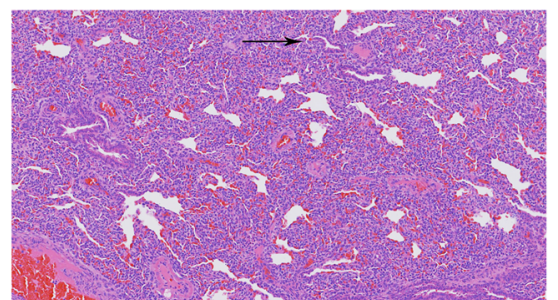

H

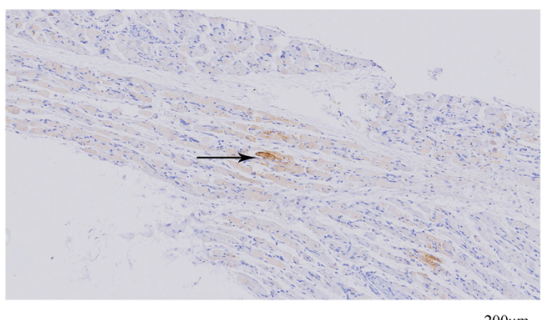

Fig. 5 Histological (a-f) and immunohistochemical ( $\mathbf{g}-\mathbf{h})$ examination of the infected neonatal mice in the moribund state. a The skeletal muscle of the mock-infected control mice. $\mathbf{b}$ The section of infected mice skeletal muscles exhibited severe necrotizing myositis (arrow). $\mathbf{c}$ The small intestine of the mock-infected control mice. $\mathbf{d}$ The section of infected mice small intestine exhibited intestinal villus interstitial edema and epithelial cell vacuolar degeneration. $\mathbf{e}$ The lung of the mock-infected control mice. $\mathbf{f}$ The section of infected mice lung exhibited severe alveolar shrinkage, vascular dilatation and congestion. $\mathbf{g}$ and $\mathbf{h}$ are based on immunohistochemical examination of the infected neonatal mice in the moribund state. $\mathbf{g}$ No viral antigen was detected in skeletal muscles of the mock control mice. $\mathbf{h}$ In contrast, distinct viral antigen was observed in skeletal muscles fibers of infected mice (arrow)

and spinal cord [22, 25-27]; In the present research, we only detected viral antigens in limb skeletal muscle of the infected mice by immunohistochemical staining, and the virus copies in limb skeletal muscles were significantly higher than those in other tissues, which suggested that the limb skeletal muscle was the primary location of viral replication. Our results mentioned above were consistent with a previous research [28], which established a neonatal mouse model directly with a CVA10 clinical strain
(CVA10-FJ-01), but not from an infectious clone. Thus, theCA10 infectious clone can be used for the preservation of specific virus strains, and it also can be used for establishment of mouse models, serving as a reference for human infection with the same virus.

\section{Conclusions}

In conclusion, we for the first time successfully established an infectious cDNA clone of CA10. The 
CA10 virus recovered from this cDNA clone was genetically and biologically identical to its parental strain, and could induce mouse's multiple tissue lesion and death after intracerebral infection, which thus could be used for establishment of a virus strain model. In brief, this study will facilitate the next researches related to the viral gene functions, pathogenesis, or vaccine development in the future.

\section{Abbreviations \\ CA10: Coxsackievirus A10; CA16: Coxsackievirus A16; CPE: Cytopathic effect: DMEM: Dulbecco's Modified Eagle Medium; ECHO: Enteric cytopathic human orphan virus; EV71: Enterovirus A71; FBS: Fetal bovine serum; HE: Hematoxylin and eosin; HFMD: Hand, foot and mouth disease; ICR: Institute of Cancer Research; IHC: Immunohistochemical; PEG: Polyethylene glycol; RD: Rhabdomyosarcoma; SPF: Specific pathogen- free; TCID50: 50\% tissue culture infectious dose}

\section{Acknowledgements}

Not applicable.

\section{Authors' contributions}

$\mathrm{HL}$ and $\mathrm{QL}$ conceived and designed the study and the experiments. QL, HD, $X Z, H C$ and $Y C$ performed the experiments. QL contributed to data analysis and manuscript preparation. HL and ZM provided critique to the manuscript. All authors have read and approved the manuscript.

\section{Funding}

This research was supported by grants from the National Natural Science Foundation of China (No. 81660280; No. 31760262) and the Guangxi Natural Science Foundation (No. 2016GXNSFAA380038; No. 2017GXNSFBA198120).

\section{Availability of data and materials}

Not applicable.

\section{Ethics approval and consent to participate}

This study was performed in strict accordance with the recommendations in the Guide for the Institutional Animal Care and Use Commission (IACUC). The protocols were approved by the Committee on the Ethics of Animal Experiments of the Guilin Medical University.

\section{Consent for publication}

Not applicable.

\section{Competing interests}

The authors declare that they have no competing interests.

\section{Author details}

'Department of Laboratory Medicine, The Second Affiliated Hospital of Guilin Medical University, Guilin, Guangxi, China. ${ }^{2}$ College of Bio-technology, Guilin Medical University, Guilin, Guangxi, China. ${ }^{3}$ College of Laboratory Medicine, Guilin Medical University, Guilin, Guangxi, China. ${ }^{4}$ Center of Diabetic Systems Medicine, Guangxi Key Laboratory of Excellence, Guilin Medical University, Guilin, China.

Received: 27 April 2019 Accepted: 18 July 2019

Published online: 06 August 2019

\section{References}

1. Aswathyraj S, Arunkumar G, Alidjinou EK, Hober D. Hand, foot and mouth disease (HFMD): emerging epidemiology and the need for a vaccine strategy. Med Microbiol Immunol. 2016;205:397-407.

2. Li W, Gao HH, Zhang Q, Liu YJ, Tao R, Cheng YP, Shu Q, Shang SQ. Large outbreak of herpangina in children caused by enterovirus in summer of 2015 in Hangzhou, China. Sci Rep. 2016;6:35388.

3. He YQ, Chen L, Xu WB, Yang H, Wang HZ, Zong WP, Xian HX, Chen HL, Yao $X J, H u Z L$, et al. Emergence, circulation, and spatiotemporal phylogenetic analysis of coxsackievirus a6- and coxsackievirus a10-associated hand, foot, and mouth disease infections from 2008 to 2012 in Shenzhen, China. J Clin Microbiol. 2013:51:3560-6.

4. Blomqvist S, Klemola P, Kaijalainen S, Paananen A, Simonen ML, Vuorinen T, Roivainen M. Co-circulation of coxsackieviruses A6 and A10 in hand, foot and mouth disease outbreak in Finland. J Clin Virol. 2010;48:49-54.

5. Mirand A, Henquell C, Archimbaud C, Ughetto S, Antona D, Bailly JL, Peigue-Lafeuille $\mathrm{H}$. Outbreak of hand, foot and mouth disease/ herpangina associated with coxsackievirus A6 and A10 infections in 2010, France: a large citywide, prospective observational study. Clin Microbiol Infect. 2012;18:E110-8.

6. Upala P, Apidechkul T, Suttana W, Kullawong N, Tamornpark R, Inta C. Molecular epidemiology and clinical features of hand, foot and mouth disease in northern Thailand in 2016: a prospective cohort study. BMC Infect Dis. 2018;18:630.

7. Hoang MTV, Nguyen TA, Tran TT, Vu TTH, Le NTN, Nguyen THN, Le THN, Nguyen TTH, Nguyen TH, Le NTN, et al. Clinical and aetiological study of hand, foot and mouth disease in southern Vietnam, 2013-2015: inpatients and outpatients. Int J Infect Dis. 2019;80:1-9.

8. Munivenkatappa A, Yadav PD, Nyayanit DA, Majumdar TD, Sangal L, Jain S, Sinha DP, Shrivastava A, Mourya DT. Molecular diversity of Coxsackievirus A10 circulating in the southern and northern region of India [2009-17]. Infect Genet Evol. 2018;66:101-10.

9. Bracho MA, Gonzalez-Candelas F, Valero A, Cordoba J, Salazar A. Enterovirus co-infections and onychomadesis after hand, foot, and mouth disease, Spain, 2008. Emerg Infect Dis. 2011;17:2223-31.

10. Okada H, Wada M, Sato H, Yamaguchi Y, Tanji H, Kurokawa K, Kawanami T, Takahashi T, Kato T. Neuromyelitis optica preceded by hyperCKemia and a possible association with coxsackie virus group A10 infection. Intern Med. 2013;52:2665-8.

11. Fuschino ME, Lamson DM, Rush K, Carbone LS, Taff ML, Hua Z, Landi K, George KS. Detection of coxsackievirus A10 in multiple tissues of a fatal infant sepsis case. J Clin Virol. 2012;53:259-61.

12. Yamashita T, Ito M, Taniguchi A, Sakae K. Prevalence of coxsackievirus A5, A6, and A10 in patients with herpangina in Aichi Prefecture, 2005. Jpn J Infect Dis. 2005;58:390-1.

13. =Guan $\mathrm{H}$, Wang J, Wang $\mathrm{C}$, Yang M, Liu L, Yang G, Ma X. Etiology of multiple non-EV71 and non-CVA16 enteroviruses associated with hand, foot and mouth disease in Jinan, China, 2009-June 2013. PLoS One. 2015;10:e0142733

14. Zhang YX, Wei T, Li XY, Yin X, Li YH, Ding JW, Zhou JM, Zhang GZ, Jin Q, Cen S. Construction and characterization of an infectious cDNA clone of enterovirus type 71 subgenotype C4. Virus Genes. 2013;47:235-43.

15. Liu F, Liu Q, Cai Y, Leng Q, Huang Z. Construction and characterization of an infectious clone of coxsackievirus A16. Virol J. 2011;8:534.

16. Yang L, Li S, Liu Y, Hou W, Lin Q, Zhao H, Xu L, He D, Ye X, Zhu H, et al. Construction and characterization of an infectious clone of coxsackievirus A6 that showed high virulence in neonatal mice. Virus Res. 2015;210:165-8.

17. Kandolf $\mathrm{R}$, Hofschneider PH. Molecular cloning of the genome of a cardiotropic Coxsackie B3 virus: full-length reverse-transcribed recombinant cDNA generates infectious virus in mammalian cells. Proc Natl Acad Sci U S A. $1985 ; 82: 4818-22$

18. Paananen A, Savolainen-Kopra C, Kaijalainen S, Vaarala O, Hovi T, Roivainen M. Genetic and phenotypic diversity of echovirus 30 strains and pathogenesis of type 1 diabetes. J Med Virol. 2007;79:945-55.

19. Hou W, Yang L, Li S, Yu H, Xu L, He D, Chen M, He S, Ye X, Que Y, et al. Construction and characterization of an infectious cDNA clone of echovirus 25. Virus Res. 2015;205:41-4.

20. Reed $\sqcup$, Muench $H$. A simple method of estimating fifty percent endpoints. Am J Hyg. 1983;27:493-7.

21. Chong P, Guo MS, Lin FH, Hsiao KN, Weng SY, Chou AH, Wang JR, Hsieh SY, Su IJ, Liu CC. Immunological and biochemical characterization of coxsackie virus A16 viral particles. PLoS One. 2012;7:e49973.

22. Mao Q, Wang Y, Gao R, Shao J, Yao X, Lang S, Wang C, Mao P, Liang Z, Wang J. A neonatal mouse model of coxsackievirus A16 for vaccine evaluation. J Virol. 2012;86:11967-76.

23. Lazouskaya NV, Palombo EA, Poh CL, Barton PA. Construction of an infectious CDNA clone of Enterovirus 71: insights into the factors ensuring experimental success. J Virol Methods. 2014;197:67-76.

24. Arita M, Shimizu H, Nagata N, Ami Y, Suzaki Y, Sata T, Iwasaki T, Miyamura T. Temperature-sensitive mutants of enterovirus 71 show attenuation in cynomolgus monkeys. J Gen Virol. 2005;86:1391-401. 
25. Li J, Chang J, Liu X, Yang J, Guo H, Wei W, Zhang W, Yu XF. Protection from lethal challenge in a neonatal mouse model by circulating recombinant form coxsackievirus A16 vaccine candidates. J Gen Virol. 2014;95:1083-93.

26. Chang J, Li J, Liu X, Liu G, Yang J, Wei W, Zhang W, Yu XF. Broad protection with an inactivated vaccine against primary-isolated lethal enterovirus 71 infection in newborn mice. BMC Microbiol. 2015;15:139.

27. Chen YC, Yu CK, Wang YF, Liu CC, Su IJ, Lei HY. A murine oral enterovirus 71 infection model with central nervous system involvement. J Gen Virol. 2004;85:69-77.

28. Li S, Zhao H, Yang L, Hou W, Xu L, Wu Y, Wang W, Chen C, Wan J, Ye X, et al. A neonatal mouse model of coxsackievirus A10 infection for anti-viral evaluation. Antivir Res. 2017;144:247-55.

\section{Publisher's Note}

Springer Nature remains neutral with regard to jurisdictional claims in published maps and institutional affiliations.

Ready to submit your research? Choose BMC and benefit from:

- fast, convenient online submission

- thorough peer review by experienced researchers in your field

- rapid publication on acceptance

- support for research data, including large and complex data types

- gold Open Access which fosters wider collaboration and increased citations

- maximum visibility for your research: over $100 \mathrm{M}$ website views per year

At $\mathrm{BMC}$, research is always in progress.

Learn more biomedcentral.com/submissions 